\title{
The BIS and hemodynamic changes in major burn patients according to a slow infusion of propofol for induction
}

\author{
Ji Young Bae ${ }^{1}$, Do Young Choi ${ }^{1}$, Chul-Ho Woo ${ }^{1}$, In-Suk Kwak ${ }^{1}$, Sung Ha Mun², and Kwang-Min Kim ${ }^{1}$ \\ Department of Anesthesiology and Pain Medicine, ${ }^{1}$ Hangang Sacred Heart Hospital, College of Medicine, Hallym University, \\ ${ }^{2}$ Kangbuk Samsung Hospital, College of Medicine, Sungkyunkwan University, Seoul, Korea
}

Background: Many pathophysiologic alterations in patients with major burns can cause changes in the response of propofol. The aim of this study is to determine the appropriate induction dose of propofol using a slow infusion rate for major burn patients to obtain desirable sedation and hypnotic conditions with minimal hemodynamic changes.

Methods: 45 adults with major burns and who were electively scheduled for escharectomy less than a week after injury were recruited. For induction with propofol, the patients were randomly allocated to one of two groups (group 1: $1.5 \mathrm{mg} / \mathrm{kg}, \mathrm{n}=20$ and group 2: $2.0 \mathrm{mg} / \mathrm{kg}, \mathrm{n}=25$ ). The infusion rate was $20 \mathrm{mg} / \mathrm{kg} / \mathrm{hr}$. The systolic and diastolic blood pressure (SBP, DBP), the heart rate, the bispectral index and the modified observers' assessment of the alertness/ sedation scale (OAA/S) were measured before the induction and after the propofol infusion, as well as immediately, 3 and 5 minutes after intubation.

Results: The SBP and DBP were significantly decreased after the propofol infusion in both group, but there were no significant differences between the two groups. The BIS values after the propofol infusion and intubation were $44.2 \pm$ 16.1 and $43.5 \pm 13.8$ in group 1, and $45.6 \pm 10.3$ and $46.5 \pm 11.4$ in group 2, respectively, and there were no differences between the 2 groups.

Conclusions: When propofol is administrated to major burn patients, an induction dose of $1.5 \mathrm{mg} / \mathrm{kg}$ is appropriate and a slow infusion rate of $20 \mathrm{mg} / \mathrm{kg} / \mathrm{hr}$ is safe for maintaining the desired hypnotic conditions and this dose and rate cause no significant hemodynamic problems. (Korean J Anesthesiol 2011; 60: 161-166)

Key Words: Bispectral index monitors, Burns, Infusions, Intravenous, Propofol.

Received: July 14, 2010. Revised: September 7, 2010. Accepted: September 24, 2010.

Corresponding author: Chul-Ho Woo, M.D., Department of Anesthesiology and Pain Medicine, Hangang Sacred Heart Hospital, Yeongdeungpo-dong 2-ga, Yeongdeungpo-gu, Seoul 150-719, Korea. Tel: 82-2-2639-5505, Fax: 82-2-2631-4387, E-mail: woochmd@naver.com (c) This is an open-access article distributed under the terms of the Creative Commons Attribution Non-Commercial License (http:// creativecommons.org/licenses/by-nc/3.0/), which permits unrestricted non-commercial use, distribution, and reproduction in any medium, provided the original work is properly cited. 


\section{Introduction}

Major burn patients experience pathophysiological changes due to the burns such as change in their metabolic function, blood flow and protein synthesis, and increased cardiac output. These affect the pharmokinetics of drugs such as drug distribution, biochemical changes and protein binding; and the clinical cases have shown that the pharmodynamic responses of major burn patients are different from those of healthy patients $[1,2]$.

Propofol has a short context-sensitive half-life and a short effect-site equilibration time. Used as a sedative and general anesthetic, its advantage lies in that it can be titrated [3]. But the arterial pressure decreases according to the anesthetic induction dose, and this is regardless of disorders of the cardiovascular system; propofol $2-2.5 \mathrm{mg} / \mathrm{kg}$ brings about a 25-40\% drop in blood pressure [4]. This occurs with a preload and afterload reduction without compensative responses such as a rise in the heart rate or cardiac output [5]. This can worsen due to factors such as a large dose and a fast infusion rate [6]. Studies on the induction doses, the anesthesia induction time and the hemodynamic changes to different propofol infusion rates have shown that the slower the infusion rate, the lower the required dose for anesthetics and the longer the time required for anesthesia induction, but the drop in blood pressure decreases [7].

In burn patients, propofol is a commonly used drug for anesthesia induction and maintenance and for sedation in the ICU. However in major burn patients, the suggested dose for propofol's intravenous administration, when used alone, is not known.

In the presented study, the authors used the BIS, which is commonly used to measure the patients' level of sedation and hypnosis, for major burn patients and the same dose of propofol as was given to healthy adult patients was infused at a slow infusion rate to determine what dose of propofal could maintain hemodynamic stability and adequate sedated and hypnotic states.

\section{Materials and Methods}

The present study received the approval from our hospital's ethics committee. The authors visited the patients and explained the details of the study. The patients then gave their written consent to participate in this study.

The patient-subjects were of the age range 18-60 years with burns that were $25 \%$ or more of the total body surface area (TBSA). They were successfully resuscitated, and they were in the acute phase within 1-week post-injury. They were ASA II and III patients scheduled for escharectomy. The patients were not given hypertensors prior to surgery in the ICU. The patients who were chosen were healthy enough to follow the requirements of the study. The patients were randomly placed in the propofol $1.5 \mathrm{mg} / \mathrm{kg}$ group (Group 1, $\mathrm{n}=20$ ) or the propofol $2.0 \mathrm{mg} / \mathrm{kg}$ group (Group 2, $\mathrm{n}=25$ ). There were no significant differences between the patient groups for age, weight or height (Table 1). Patients were excluded from the study if they had a past history of disorders of the heart, liver, kidney and/or central nervous system, if they had taken sedatives or sleeping pills for a long period, and if they were pregnant or allergic to propofol. The patients with facial burns were excluded from the study because of their difficulty have BIS sensors attached.

There was no premedication given because it has a sedative effect and an effect on the cardiovascular system. Upon arriving on the surgery table the patient was stabilized; afterwards the EKG, the noninvasive blood pressure monitor and the pulseoximeter were attached. To evaluate the depth of sedation, BIS monitor (A-3000 BIS monitor, Aspect Medical System, USA) sensors (BIS ${ }^{\mathrm{TM}}$ Quatro, Aspect Medical system, Norwood, MA) were attached to the patient's forehead and between the eyes and hairline. After confirming that the BIS values showed no interference, the wrist was anesthetized for A-line monitoring with local anesthetics. The radial artery was cannulated. At this point the blood pressure, heart rate and BIS values were taken for the baseline measurements. The BIS values were recorded after 15 seconds.

All the patients were given $100 \%$ oxygen at $10 \mathrm{~L} / \mathrm{min}$ for 5 minutes for preoxygenation. Normal saline $150-200 \mathrm{ml}$ was intravenously administered through the central vein before anesthesia induction. Afterwards, a mask was placed on the patient to assist breathing. Using an infusion pump (Terufusion Syringe Pump TE-311, Japan) 1\% propofol (Fresofol 1\%, Fresenius Kabi, Austria) at $1.5 \mathrm{mg} / \mathrm{kg}$ was administered to the Group 1 patients and $2.0 \mathrm{mg} / \mathrm{kg}$ propofol was administered to Group 2 at $20 \mathrm{mg} / \mathrm{kg} / \mathrm{hr}$. When the dose was completely infused, the blood pressure, heart rate, OAA/S (modified observer's assessment of alertness/sedation scale) and BIS value were recorded (Table 2). If the systolic pressure was

Table 1. Patient Characteristics

\begin{tabular}{lcc}
\hline & Group 1 (n=20) & Group 2 (n=25) \\
\hline Age (yr) & $43.1 \pm 12.1$ & $45.2 \pm 12.4$ \\
Body weight (kg) & $63.0 \pm 10.5$ & $65.4 \pm 12.9$ \\
Height (cm) & $166.5 \pm 9.3$ & $167.1 \pm 7.2$ \\
Gender (M/F) & $16 / 4$ & $17 / 8$ \\
Total body surface area (\%) & $29.7 \pm 4.6$ & $30.2 \pm 4.7$ \\
Elapsed time from burn (day) & $5.6 \pm 1.1$ & $5.4 \pm 1.2$ \\
\hline
\end{tabular}

Values are means \pm SDs or the number of patients. There were no significant differences between the two groups. Group 1: propofol 1.5 $\mathrm{mg} / \mathrm{kg}$, Group 2: propofol $2.0 \mathrm{mg} / \mathrm{kg}$. 
reduced to below $75 \mathrm{mmHg}$ or $40 \%$ or more of the baseline blood pressure, then ephedrine was used to adjust the blood pressure. After the drug was completely infused, rocuronium $1.0 \mathrm{mg} / \mathrm{kg}$ was immediately intravenously administered. After adequate muscle relaxation, one third-year resident performed all the endotracheal intubations. The appropriate location of the endotracheal tube was confirmed by monitoring the endtidal $\mathrm{CO}_{2}\left(\mathrm{ETCO}_{2}\right)$ and by auscultation. Mechanical ventilation was performed with fresh $\mathrm{O}_{2}$ at $3 \mathrm{~L} / \mathrm{min}$. The $\mathrm{PETCO}_{2}$ was maintained at around $32-34 \mathrm{mmHg}$. Immediately after endotracheal intubation, propofol was continuously infused at $100 \mu \mathrm{g} / \mathrm{kg} / \mathrm{min}$. The blood pressure, heart rate and BIS value were recorded immediately, $3 \mathrm{~min}$ and $5 \mathrm{~min}$ after extubation. The day after surgery, the patient was visited to check if he or she recalled the beginning point of anesthesia.

The results are expressed as means \pm standard deviation. The statistical analysis was performed using SPSS (version 13.0, SPSS, USA). Independent sample t-tests were performed to

Table 2. Responsiveness Scores of the Modified Observer's Assessment of Alertness/Sedation Scale

\begin{tabular}{lc}
\hline Response & Score level \\
\hline $\begin{array}{l}\text { Responds readily to their name spoken in a normal tone } \\
\text { Lethargic response to their name spoken in a normal } \\
\text { tone }\end{array}$ & 5 \\
$\begin{array}{l}\text { Response only after their name is called loudly and/or } \\
\text { repeatedly }\end{array}$ & 3 \\
$\begin{array}{l}\text { Response only after name spoken with mild prodding } \\
\text { or shaking }\end{array}$ & 2 \\
$\begin{array}{l}\text { Does not respond to mild prodding or shaking } \\
\text { Does not respond to noxious stimuli (Trapezius squeezing) }\end{array}$ & 0 \\
\hline
\end{tabular}

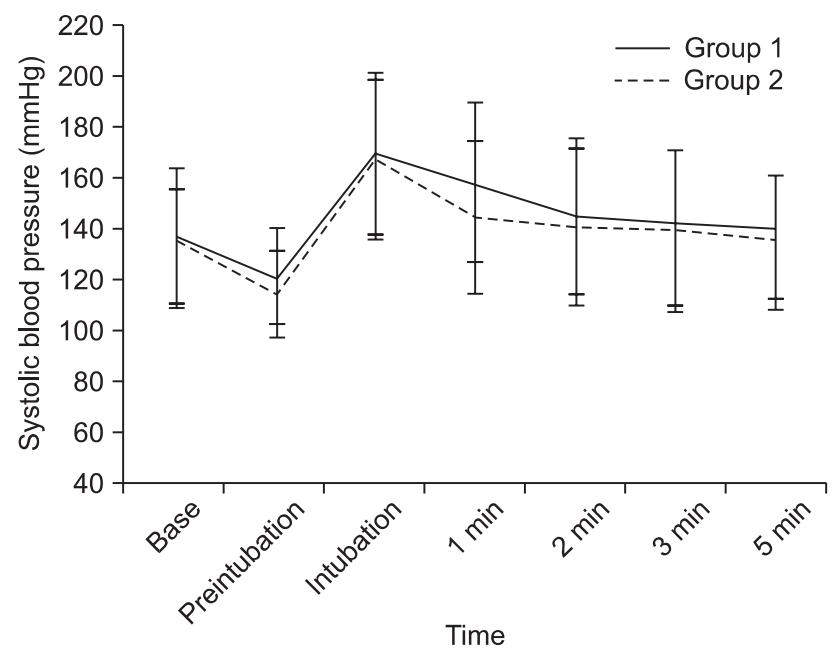

Fig. 1. Changes of the systolic blood pressure (SBP). There were no significant differences between the two groups. Preintubation: after propofol infusion, Intubation: immediately after intubation, 1, 2, 3 and 5 min: 1, 2, 3 and 5 minutes after intubation. Group 1: propofol $1.5 \mathrm{mg} / \mathrm{kg}$, Group 2: propofol $2.0 \mathrm{mg} / \mathrm{kg}$. compare the two groups. Within each group, each point was analyzed using repeated measures of ANOVA. A P value less 0.05 was considered statistically significant.

\section{Results}

The severity of the burn based on the Classic Lund and Browder chart in the two groups was on average about $30 \%$ TBSA. The time that elapsed since the injury was 5 days (Table 1 ). Compared to the baseline value, the systolic pressure after the propofol was intravenously administered decreased by $11.5 \%$ in Group 1 and $16.3 \%$ in Group 2. This decrease was significant in both groups. Immediately after endotracheal intubation, the systolic pressure significantly rose by $24.9 \%$ in Group 1 and by $22 \%$ in Group $2(\mathrm{P}<0.05)$. However, there were no significant differences between the two groups for the blood pressure changes (Fig. 1). The diastolic pressure showed the same pattern as the systolic pressure (Fig. 2). Ephedrine was not used for any patients in both groups for controlling blood pressure. There were no differences of the heart rates that were measured at the specified periods between the groups. But the heart rate in the two groups immediately after intubation was significantly increased compared to the baseline values $(\mathrm{P}<0.05)$ (Fig. 3).

The BIS values immediately before intubation in Group 1 and Group 2 were $44.2 \pm 16.1$ and $43.5 \pm 13.8$, respectively. Immediately after intubation, they were $45.6 \pm 10.3$ and 46.5 \pm 11.4 , respectively, and there was no significant difference between the two groups. At all times except for when the drugs were infused, the appropriate BIS range for general anesthesia was maintained (Fig. 4).

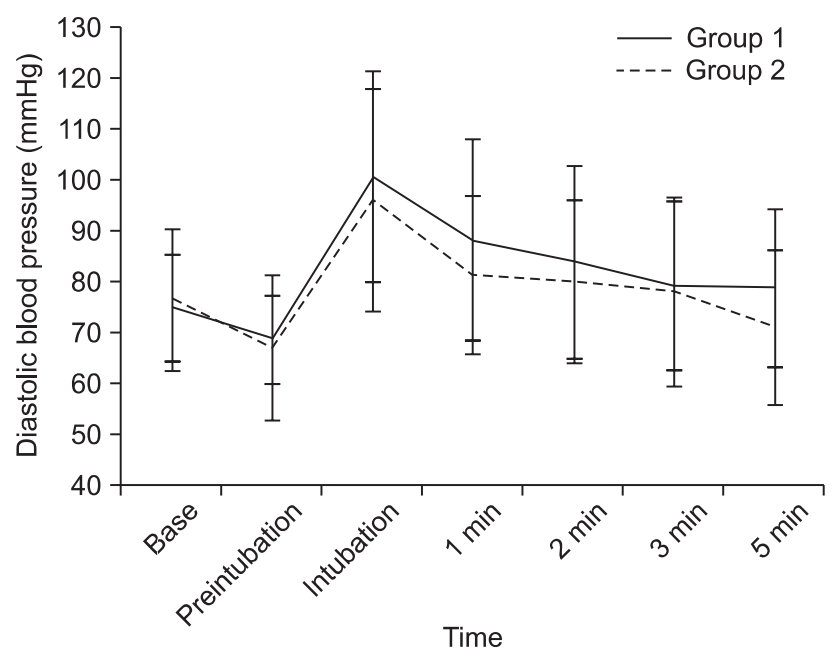

Fig. 2. Changes of the diastolic blood pressure (DBP). There were no significant differences between the two groups. Preintubation: after propofol infusion, Intubation: immediately after intubation, 1, 2, 3 and 5 min: 1, 2, 3 and 5 minutes after intubation. Group 1: propofol $1.5 \mathrm{mg} / \mathrm{kg}$, Group 2: propofol $2.0 \mathrm{mg} / \mathrm{kg}$. 


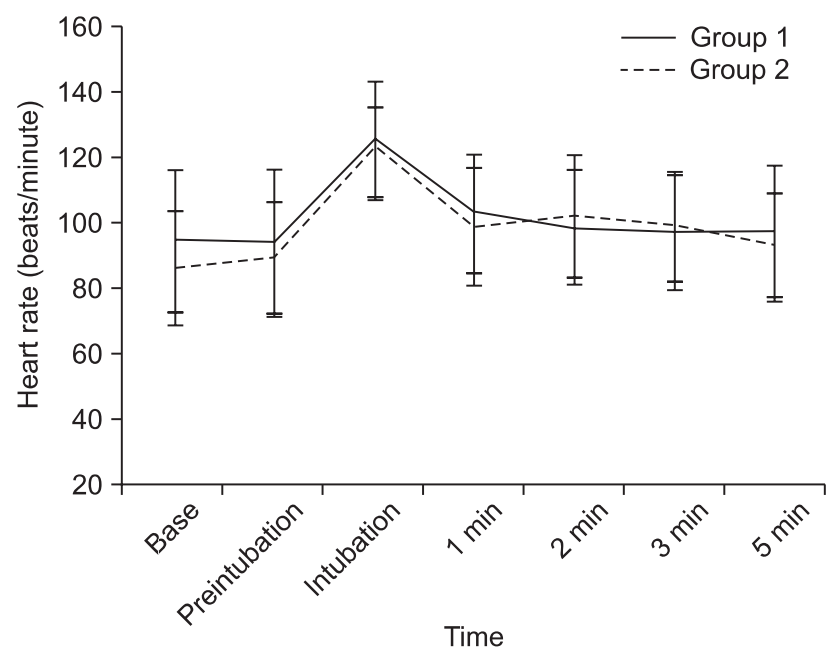

Fig. 3. Changes of heart rate (HR). There were no significant differences between the two groups. Preintubation: after propofol infusion, Intubation: immediately after intubation, 1, 2, 3 and $5 \mathrm{~min}$ : 1, 2, 3 and 5 minutes after intubation. Group 1: propofol $1.5 \mathrm{mg} / \mathrm{kg}$, Group 2: propofol $2.0 \mathrm{mg} / \mathrm{kg}$.

The OAA/S scores after propofol infusion were 95\% in Group 1 and they were between $96 \%$ and 1 in Group 2. None of the patients in either of the two groups had any recall of the surgery.

\section{Discussion}

Different patients have various responses to the use of propofol. So the dose should be titrated according to the situation and according to the patient's condition. The factors affecting the decision for the dose of propofol dose are gender, age, weight, the patient's condition, the type of surgery and the drugs that are used in combination with propofol [4].

Major burn patients with great tissue damage experience ischemia-reperfusion injury and excessive fluid resuscitation from burn shock, which cause secondary complications and systemic inflammation [8]. Hypovolemia, a reduction of the cardiac output, increased pulmonary vascular resistance and erythropyknosis also occur. If resuscitation is successful 2448 hours post-injury, then a hypermetabolic state follows. This is characterized by an increase in oxygen consumption, $\mathrm{CO}_{2}$ production and the cardiac output, and tachycardia occurs too. This state may continue for 24 months until the burns completely heal [9]. Generally after the resuscitation from all types of trauma and including burns, the functional extracellular and intracellular volumes increase [10]. The great quantity of fluid that must be administered for the purpose of resuscitation usually worsens the increased capillary permeability and interstitial edema. Burns make body fluid loss in the area of the wound inevitable [11]. At this point the intravascular volume relatively decreases, which may cause the

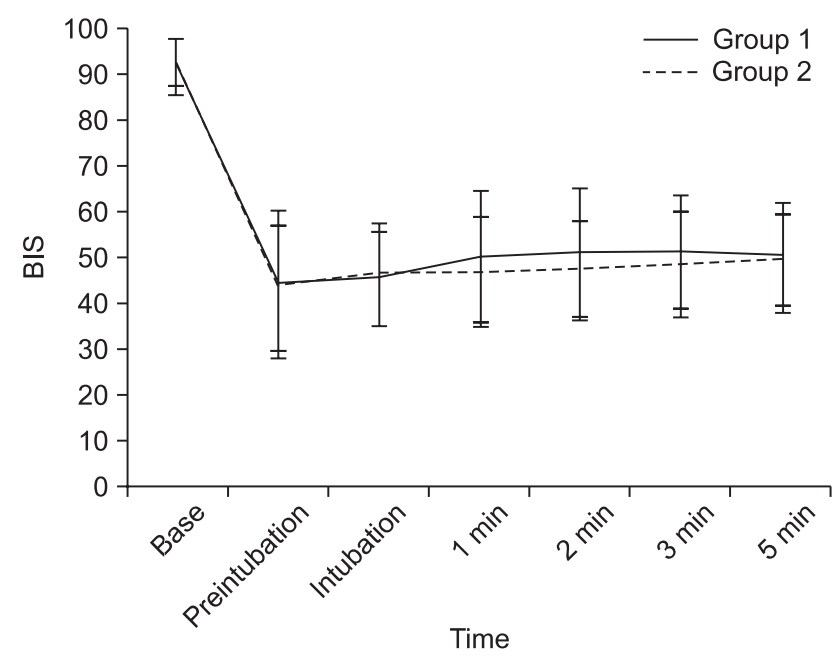

Fig. 4. Changes of the bispectral index (BIS) values. Preintubation: immediately before intubation, Intubation: after propofol infusion, 1, 2, 3 and 5 min: 1, 2, 3 and 5 minutes after intubation. Group 1: propofol $1.5 \mathrm{mg} / \mathrm{kg}$, Group 2: propofol $2.0 \mathrm{mg} / \mathrm{kg}$.

patient to have a reaction to the drugs that change intravascular resistance. So when handling patients with major burns, one must be aware of such severe hemodynamic changes and be cautious and aware of the distribution of the generally used anesthetics and the changes in response to them.

One study on the effects of burns on the pharmokinetics of propofol in pediatric patients with minor burns showed that the required dose of propofol was increased [12]. In a patient who is in a hypermetabolic state from major burns, there is an increase in the clearance rate of propofol and an increase in the volume of distribution, so there is an opinion that the initial dose or maintenance dose needs to be increased [13]. However in the present study, on deciding the total dose of propofol for the major burn patients, we took into consideration the relative hypovolemia and hemodynamic variability that can be caused by the drugs. We first started at a range similar to what would be used in generally healthy patients and then we moved to 1.5 $\mathrm{mg} / \mathrm{kg}$ and $2.0 \mathrm{mg} / \mathrm{kg}$. The patients were administered propofol at a slow infusion rate of $20 \mathrm{mg} / \mathrm{kg} / \mathrm{hr}$. The sedated states, hypnotic states and hemodynamic changes were monitored. The two groups did not have significant differences of their systolic pressure, diastolic pressure or heart rate. Propofol $1.5 \mathrm{mg} / \mathrm{kg}$ and $2.0 \mathrm{mg} / \mathrm{kg}$ were infused with the patients in a sedated and hypnotic state, which were appropriate doses for the two groups. So it appears that a slow infusion of propofol beyond $1.5 \mathrm{mg} / \mathrm{kg}$ is unnecessary even in burn patients. In fact, for the dose of $1.5 \mathrm{mg} / \mathrm{kg}$, the BIS values of the patients were adequately decreased, and after propofol infusion, the inhibitory effect on the cardiovascular system was not great. Considering that the patients mostly showed tachycardia, this 
is believed to be due to their probable hypermetabolic state with an increased cardiac output, their pre-administration of crystalloid solution of $150-200 \mathrm{ml}$ and the slow infusion of 20 $\mathrm{mg} / \mathrm{kg} / \mathrm{hr}$ of propofol.

The dose of propofol for the induction of anesthesia for a healthy adult is $1-2.5 \mathrm{mg} / \mathrm{kg}$. The suggested infusion rate for propofol is $100-200 \mu \mathrm{g} / \mathrm{kg} / \mathrm{min}$. For fast induction of anesthesia, the infusion rate is $80 \mathrm{mg} / \mathrm{kg} / \mathrm{hr}$ [4]. In the present study the anesthesia doses were set as $1.5 \mathrm{mg} / \mathrm{kg}$ and $2.0 \mathrm{mg} / \mathrm{kg}$. After the doses were completely infused, the infusion rate was set at a slow rate of $20 \mathrm{mg} / \mathrm{kg} / \mathrm{hr}$. The infusion rate for anesthesia maintenance was set at $100 \mu \mathrm{g} / \mathrm{kg} / \mathrm{min}$. In all the phases, the BIS value was below 65 . So, these were confirmed as the suitable total dose and maintenance rates for maintaining anesthesia in major burn patients without complications.

Generally, the responses to oral command are checked during the evaluation of loss of consciousness. In the present study, as an assessment tool for sedation, a modified OAA/S score and the BIS, which are commonly used to check the state of sedation and hypnosis, were used in order to compare the differences between the two groups. The correlation between the OAA/ $\mathrm{S}$ score and the BIS and the correlation between the effect-site concentration of BIS and propofol were reported to be very positive $[14,15]$. BIS values of $40-65$ are the suggested range for a patient under general anesthesia; $65-85$ is for a sedated state, but alertness is possible [16]. A BIS value of 65 or above and 2 on the OAA/S score is not adequate for achieving hypnosis for endotracheal intubation. In both groups of the present study, after the intravenous infusion of drugs and immediately after endotracheal intubation, the BIS value was 65 or below, which was appropriate for general anesthesia. In the present study 1 patient in Group $1(5 \%)$ and 1 patient (4\%) in Group 2 showed an OAA/S of 2 . But both patients showed a BIS value of 65 or below. There was positive correlation between the BIS and OAA/S. Yet it is hard to remove the observer's bias. So for inducing anesthesia, the BIS is considered the more appropriate method for evaluating the appropriate state of hypnosis.

It is known that the slower the infusion rate of propofol, the smaller are the hemodynamic changes, a lesser quantity of propofol is required for anesthesia and the anesthesia time is longer $[7,17]$. In the present study the slow infusion rate resulted in the reduction of the systolic pressure by $11.5 \%$ and $16.3 \%$ in the groups, which is $25-40 \%$ lower than the usual reduction rate, confirming that slow infusion is a safe method.

However, this is the first limitation of our study. The induction time was long: it was a mean of $4.5 \mathrm{~min}$ in Group 1 and $6 \mathrm{~min}$ in Group 2. In both groups, the lowest systolic pressure was at the time point after propofol infusion, but immediately before endotracheal intubation. There was no case of hypotension that required drug treatment. Further studies with faster infusion should be conducted in order to achieve safer and faster anesthesia induction. The second drawback of the present study was that there was no management for the elevation of the blood pressure and heart rate due to the irritation from the endotracheal tube. Using opioids is beneficial for the ideal circumstance for endotracheal intubation [18]. But opioid can affect the BIS, so the combined use of drugs that do not affect the BIS values but that can still prevent elevation of the systolic pressure and heart rate, such as esmolol, should be considered [19]. In this study, there were no differences in the changes of the systolic pressure between the two groups. So rather than raising the dose of propofol to increase the difference in hemodynamic changes, the use of hypotensors is considered more appropriate. The third drawback was that patients with burns of more than $40 \%$ of the TBSA and this is accompanied with burns on the face, head and neck area were not included in this study. Major burns are defined as more than $25 \%$ of the TBSA. Patients with more severe burns are expected to have greater hemodynamic changes. So if such patients as mentioned above had been included, the study would have been more comprehensive. It is difficult to attach sensors on patients with face, head and neck burn, as the attachment may cause skin damage. BIS values cannot be taken for these patients. So we think that an alternative method to directly attach sensors to the skin needs to be found.

In conclusion, for continuous infusion for the prevention of hypotension, a $1.5 \mathrm{mg} / \mathrm{kg}$ dose slowly infused at the rate 20 $\mathrm{mg} / \mathrm{kg} / \mathrm{hr}$ will not cause a significant decrease in the blood pressure and it will maintain an adequate hypnotic state for general anesthesia even in major burn patients. Moreover, a slow infusion of propofol is safe for reducing the induction time. However, further studies that will focus on rates of infusion are needed.

\section{References}

1. Jaehde U, Sörgel F. Clinical pharmacokinetics in patients with burns. Clin Pharmacokinet 1995; 29: 15-28.

2. Martyn J. Clinical pharmacology and drug therapy in the burned patient. Anesthesiology 1986; 65: 67-75.

3. Hiller SC, Mazurek MS. Monitored Anesthesia care. In: Clinical Anesthesia. 5th ed. Edited by Barash PG, Cullen BF, Stoelting RK: Philadelphia, Lippincott Williams \& Wilkins. 2006, pp 1246-61.

4. Reves JG, Glass P, Lubarsky DA, McEvoy MD, Martinez-Ruiz R. Intravenous anesthesia. In: Anesthesia. 7th ed. Edited by Miller RD: New York, Churchill Livingstone. 2010, pp 719-58.

5. Schmidt C, Roosens C, Struys M, Deryck YL, Van Nooten G, Colardyn F, et al. Contractility in humans after coronary artery surgery. Anesthesiology 1999; 91: 58-70.

6. Morgan GE, Mikhail MS, Murray MJ. Clinical Anesthesiology. 4th ed. New York, McGraw-Hill. 2006, pp 200-2.

7. Stokes DN, Hutton P. Rate-dependent induction phenomena 
with propofol: implications for the relative potency of intravenous anesthetics. Anesth Analg 1991; 72: 578-83.

8. Murphey ED, Sherwood ER, Toliver-Kinsky T. The immunological response and strategies for intervention. In: Total burn care. 3rd ed. Edited by Herndon DN: Philadelphia, Saunders. 2007, pp 310-24.

9. Herndon DN, Tompkins RG. Support of the metabolic response to burn injury. Lancet 2004; 363: 1895-902.

10. Wilmore DW. Metabolic response to severe surgical illness: overview. World J Surg 2000; 24: 705-11.

11. Woodson LC, Sherwood ER, Aarsland A, Talon M, Kinsky MP, Morvant EM. Anesthesia for burned patients. In: Total burn care. 3rd ed. Edited by Herndon DN: Philadelphia, Saunders. 2007, pp 196-228.

12. Murat I, Billard V, Vernois J, Zaouter M, Marsol P, Souron R, et al. Pharmacokinetics of propofol after a single dose in children aged 1-3 years with minor burns. Comparison of three data analysis approaches. Anesthesiology 1996; 84: 526-32.

13. Kwak IS, Jung SW, Lee JY, Jung MH, Choi YR, Won RS, et al. Enhanced clearance of propofol in patients with major burns. Korean J Anesthesiol 2006; 51: 285-91.

14. Kim KS, Bae HB, Choi JC, Kim SJ, Chung SS, Yoo KY, et al. Correlations between the modified observer's assessment of alertness/sedation scale, bispectral index and propofol effect site concentrations in sedated elderly patients under regional anesthesia. Korean J Anesthesiol 2005; 49: 349-54.

15. Glass PS, Bloom M, Kearse L, Rosow C, Sebel P, Manberg P. Bispectral analysis measures sedation and memory effects of propofol, midazolam, isoflurane, and alfentanil in healthy volunteers. Anesthesiology 1997; 86: 836-47.

16. Johansen JW, Sebel PS. Development and clinical application of electroencephalographic bispectrum monitoring. Anesthesiology 2000; 93: 1336-44

17. Kazama T, Ikeda K, Morita K, Kikura M, Ikeda T, Kurita T, et al. Investigation of effective anesthesia induction doses using a wide range of infusion rates with undiluted and diluted propofol. Anesthesiology 2000; 92: 1017-28.

18. Mi WD, Sakai T, Singh H, Kudo T, Kudo M, Matsuki A. Hypnotic endpoints vs. the bispectral index, $95 \%$ spectral edge frequency and median frequency during propofol infusion with or without fentanyl. Eur J Anaesthesiol 1999; 16: 47-52.

19. Berkenstadt H, Loebstein R, Faibishenko I, Halkin H, Keidan I, Perel A. Effect of a single dose of esmolol on the bispectral index scale (BIS) during propofol/fentanyl anaesthesia. Br J Anaesth 2002; 89: 509-11. 